Éducation

et sociétés

plurilingues

\section{Éducation et sociétés plurilingues}

$38 \mid 2015$

Varia

\title{
La experiencia de la Escuela Argentina en París
}

Un proyecto colectivo en torno a la transmisión de la lengua y la cultura

Liana Back, Lucía Dumazet y Melisa Guerrien

\section{(2) OpenEdition}

\section{Journals}

Edición electrónica

URL: http://journals.openedition.org/esp/564

DOI: $10.4000 /$ esp. 564

ISSN: 2532-0319

\section{Editor}

Centre d'Information sur l'Éducation Bilingue et Plurilingue

\section{Edición impresa}

Fecha de publicación: 1 junio 2015

Paginación: 87-96

ISSN: 1127-266X

\section{Referencia electrónica}

Liana Back, Lucía Dumazet y Melisa Guerrien, «La experiencia de la Escuela Argentina en París», Éducation et sociétés plurilingues [En línea], 38 | 2015, Puesto en línea el 01 marzo 2016, consultado el 25 febrero 2021. URL: http://journals.openedition.org/esp/564 ; DOI: https://doi.org/10.4000/esp.564 


\section{LA EXPERIENCIA DE LA ESCUELA ARGENTINA EN PARÍS. UN PROYECTO COLECTIVO EN TORNO A LA TRANSMISIÓN DE LA LENGUA Y LA CULTURA}

\section{Liana BAGK (en colaboración con Lucía DuMAZET et Melisa GUERRIEN)}

Da quasi dieci anni un gruppo di famiglie franco-argentine, desiderose di mantenere tramite $i$ loro figli una doppia filiazione culturale, ha iniziato a Parigi l'avventura di creare una struttura educativa che permetta ai bambini franco-argentini di incontrarsi e sviluppare quest'identità ancora in divenire all'interno di un quadro istituzionale. Come dare ai bambini gli strumenti per sviluppare un'identità franco-argentina pur vivendo immersi nella realtà francese? La proposta della Scuola Argentina di Parigi (ESP) è di offrire un'istituzione in cui $i$ bambini possano costruirsi un'appartenenza in armonia con un mondo aperto e multilingue. In cui la loro realtà francese e la loro visione del mondo europea si nutrano dell'apporto della cultura argentina e latino-americana, facilitando l'integrazione nel mondo contemporaneo.

Depuis presque dix ans, un groupe de familles franco-argentines, désireuses de maintenir au travers de leurs enfants une double filiation culturelle, a initié à Paris l'aventure de créer une structure éducative qui permette aux enfants franco-argentins de se rencontrer et de développer cette identité encore en devenir au sein d'un cadre institutionnel. Comment donner aux enfants les outils pour développer une identité franco-argentine tout en vivant immergés dans la réalité française? La proposition de l'École Argentine à Paris (EAP) est d'offrir une institution où les enfants puissent se construire une appartenance en harmonie avec un monde ouvert et multilingue. Où leur réalité française et leur vision européenne du monde se nourrit de l'apport de la culture argentine et latino-américaine, facilitant l'intégration dans le monde contemporain.

About ten years ago, wishing to maintain the children's dual cultural heritage, a group of French-Argentinian families created an educational structure in Paris in order to allow their budding identity to develop within an institutional framework. How could the children be given the tools to develop their identities as French and Argentine while growing up immersed in French realities? The EAP (École Argentine à Paris) offers the possibility of constructing a sense of belonging in harmony with an open and multilingual universe. Their French experience and European vision of the world is enriched by contributions from Argentina and Latin America, facilitating their integration into contemporary life.

Key-words: Franco-Argentine School in Paris, dual culture, dual identities, multilingualism

\section{INTRODUCGIÓN}

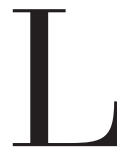

a Escuela Argentina en París (EAP) es una escuela complementaria que nació en septiembre del 2009 para niños bilingües (español-francés) nacidos en Francia en el seno de familias mixtas instaladas en la región de Ile de France.

El proyecto institucional y pedagógico fue fundado por un grupo de familias mixtas deseosas de transmitir su cultura y su lengua a sus niños "franceses" en un contexto institucional y extrafamiliar.

Las escuelas complementarias argentinas en el mundo son cinco (tres 
La experiencia de la Escuela Argentina en París.

L. BACK (EN COLABORACIÓN CON

L. Dumazet et M. Guerrien)

\section{LA ASOCIACIÓN}

en Estados Unidos, una en Suiza y la nuestra en París). Estas escuelasLas mismas están reguladas por un decreto del Ministerio de Educación argentino que encuadra su funcionamientoy. Estas escuelas son suponen un complemento de educación para niños, nacidos en el seno de familias mixtas y/o expatriadas, escolarizados en las instituciones locales. Los contenidos pedagógicos corresponden a las áreas de ciencias sociales, lengua y literatura, cultura argentina y latinoamericana y formación ética y ciudadana.

En el año 2005 nace "Manuelita" un grupo de juegos mensual. Por entonces, un grupo de familias se reunían asegurando un entorno lingüistico argentino mientras compartían con los niños canciones y juegos en el liwing de sus casas.

En el 2008, convocando artistas y artesanos argentinos, la asociación crea además talleres multidisciplinarios en español; dos sábados al mes los niños "experimentaban" actividades plásticas, técnicas de reciclaje de papel, música, lectura de cuentos, siempre en español.

Sin embargo, la necesidad de un complemento de educación con un proyecto pedagógico global y una participación regular, se imponía como necesaria. En efecto, los niños en edad escolar pasaban cada vez más tiempo inmersos en el francés, y el español parecía perder terreno. Nuestras lecturas especializadas y los profesionales del bilingüismo que consultábamos nos aconsejaban mulplicar los espacios en español. Un idioma se mantiene vivo cuando se lo utiliza. La amenaza parecía real y la premonición parecía cumplirse. Nuestros niños decían "maman" en lugar de mamá, no se lastimaban, "se hacían mal" y construían frases improbables como "el auto mucho máàs grande del mundo". De estas inquietudes y presunciones nació el proyecto de una escuela complementaria argentina.

Las cinco familias fundadoras, cinco mujeres argentinas casadas con franceses, provienen de horizontes diversos: una diseñadora gráfica y mediadora cultural, dos científicas, una psicóloga/psicoanalista y una gerentea de programación de multimedia. Habiéndose todas integrado todas sin mayor dificultad a la cultura francesa, trabajan y desarrollan una vida social y familiar abierta y multicultural. Destaquemos que ninguna "sufría la lejanía" o sentía algo parecido al desarraigo, ni era nostálgica de una vida anterior en argentino. Del lado de los padres la misma diversidad, sin embargo todos han vivido en Argentina, conocen las costumbres locales, son adeptos de la cultura y hablan español. Si bien en la organización, y en la presencia, las mujeres son las que se encuentran en primer plano, los cónyuges franceses están implicados y asociados al proyecto en todas las instancias.

El proyecto naciente será el fruto de los deseos familiares de mantener 
La experiencia de la Escuela Argentina en París.

L. BACK (EN COLABORACIÓN CON

L. Dumazet et M. GuerRien) los lazos con una lengua y una cultura altamente valorada/afectivizada y del encuentro "azaroso" de este grupo de familias que, sin conocerse previamente, cruzan sus caminos compartiendo las mismas inquietudes parentales.

La vida asociativa se agranda y el proyecto crece año tras año. En el 2009, había son veinticinco niños inscriptos de 4 a 10 años repartidos en dos salas; el Comité de Administracióon (CA) está compuesto por cinco miembros voluntarios, el equipo pedagógico cuenta con cuatro docentes remunerados.

En la actualidad recibimos noventa niños y adolescentes; el equipo pedagógico cuenta con nueve docentes, una coordinadora pedagógica y una secretaria de dirección; los miembros del CAi son nueve, uno de ellos ejerce el rol de dirección o coordinación de la escuela, siendo el puente entre el proyecto institucional sostenido por la asociación y el trabajo pedagógico a cargo de los docentes.

En el camino se han creado nuevos cargos remunerados y el funcionamiento asociativo se ha complejizado. La vida asociativa no se reduce a la gestión administrativa de la escuela, $;$ al contrario. ! Las familias mixtas son el corazón del proyecto institucional, y es gracias a su implicación cotidiana y a sus reflexiones incesantes que la EAP crece y se enriquece.

Las misiones anuales del CA son variadas y comprenden desde la búsqueda de financiamiento y la representación frente a las autoridades, a la facilitación de encuentros entre familias (participación a mesas redondas, encuentros con escritores, intelectuales y artistas, presentación de películasfilms...) o la organización de actividades extra-escolares para los niños (fin de semana en el campo, participación en el Salón del Libro, visita a un museo, talleres). Muchas de estas misiones se comparten entre los miembros voluntarios teniendo en cuenta afinidades o deseos personales. Así fueron elegidos los cargos y también las tareas; por ejemplo, las plaquetas de presentación o comunicados de prensa están en manos de "nuestra" diseñadora gráfica, nuestra biblioteca fue desarrollada por el deseo tenaz de un miembro fundador. Pero como los lazos de cooperación entre miembros, adherentes y equipo pedagógico son múltiples, también pueden ocuparse de estas misiones un docente (los encuentros con los escritores argentinos de visita en París pueden estar a cargo de la coordinadora pedagógica de la escuela, o de una profesora de letras miembro del equipo); o un miembro de alguna familia (por ejemplo, una mamá antropóloga organiza una visita a la colección latinoamericana del Musée du Quai Branly; y una mamáu otra bióloga, organiza una visita a la Galería de la Evolución.)

El CA se reúne cada seis u ocho semanas, para renovar las reflexiones y avanzar en los diferentes objetivos trazados (modernización del sitio web, participación en un evento cultural, funcionamiento de la bibliote- 
La experiencia de la Escuela Argentina en París.

L. BACK (EN COLABORACIÓN CON

L. Dumazet et M. GuerRien)

\section{POBLACIÓN}

ca). Y una vez al año se realiza una Asamblea General en la que se presenta a todos los miembros (madres y padres de los alumnos) el balance anual de actividades, la vida institucional y los aspectos financieros; luego de lo cual se votan los lineamientos para el siguiente año.

Así fue como la asociación/institucióon debió encontrar los medios democráticos para ordenar tareas, elegir roles y funciones, sin construir compartimentos estancos o jerarquías marcadas. Los roles se imbrincan y se dan sentido mutuamente, pues sin las inquietudes parentales, la EAP no hubiera existido. Las reflexiones se enriquecen con el crecimiento de nuestros hijos. Nuevas problemáticas aparecen con la integración de otras familias colombianas, chilenas o uruguayas. Aparecen Nnuevos obstáculos, que hay que solventar, a trabajar con el crecimiento de la institución (la búsqueda de espacios, por ejemplo). El proyecto que nace ligado a nuestras inquietudes poco a poco se distancia del "nosotros", "lo mío", "yo", para enriquecerse con "el otro"; reflejando y elaborando otras realidades (recibiendo niños de tercera generación de inmigrantes, familias argentinas expatriadas, o mixtas con padres ni argentinos ni franceses).

Y cada miembro de la escuela trabaja consigo mismo, y en colectivo, la distancia entre ser adultos decisionarios en la institución, y ser los padres de los niños de la escuela.

La escuela abrió sus puertas en septiembre del 2009 con veintisiete niños, y mantuvo una progresión constante desde hace cinco años. En la actualidad, la inscripción se mantiene entre ochenta y cien niños, para poder asegurar el respeto a un proyecto pedagógico centrado en el acompañamiento individualizado de cada niño y de cada familia.

Los niños son bilingües, nacidos en Francia en el seno de familias mixtas. El español es la segunda lengua (L2), el francés es la lengua privilegiada, el entorno lingüístico (Ll).

En su gran mayoría solo conocen el país de origen del padre latinoamericano a través del acercamiento por la familia y los viajes de vacaciones. Todos tienen vínculos afectivos aquí y allá, todos desean mantener y enriquecer esa doble pertenencia cultural.

En lo relativo a las familias francoargentinas que concurren a la EAP, pertenecen en su mayoría a la clase media. Esto se debe a una característica específica de la inmigración argentina en Francia :: la mayoría forman parte de la inmigración de la década de los 90 y 2000. En Lla década de los 90 tiene lugarcorresponde a la implantación de numerosas empresas francesas en Argentina (Telecom, Danone,...), los jóvenes franceses se instalan y establecen lazos duraderos, en algunos casos vuelven a Francia con una familia mixta nacida allá ; y luego en los años 2000 tiene lugar ael "exilio económico" debido a la crisis económica y 
La experiencia de la Escuela Argentina en París.

L. BACK (EN COLABORACIÓN CON

L. Dumazet et M. GuerRien) bancaria, conocida como la "generación corralito". Este grupo de familias instaladas en Francia, nunca ha "cortado" los lazos con el país, viaja regularmente y eligió instalarse aquí con un proyecto laboral y familiar. Muchos de los cónyuges franceses han trabajado en Argentina y los cónyuges argentinos se instalan en Francia conociendo en parte la lengua y la cultura, rápidamente elaboran un proyecto de estudios o se insertan laboralmente. Esta continuidad entre los dos países, tanto en la realidad efectiva (inserción económica, conocimiento del idioma y de la cultura) y afectiva (lazos familiares y de amistad) caracteriza a un gran porcentaje de las familias de la escuela y es particular a esta inmigración.

La escuela recibe algunos nietos de las familias del exilio de la década de los 70, que debieron escapar a las dictaduras militares instaladas en latinoamérica, que conocieron la ruptura con el país que, a través de sus gobiernos de facto, los persiguió e hizo "desaparecer" a una parte de su entorno. Estas familias, se establecieron en Francia refugiándose, para salvar sus vidas, solo pudieron regresar al país una vez acabadas las dictaduras en la segunda mitad de la década de los 80 y muchos nunca han podido hacerlo impedidos por el aspecto traumático que ronda a este exilio. Algunos de esos padres, que hoy son abuelos, han podido elaborar los efectos psíquicos de este trauma para mantener la cultura y volver a establecer lazos con Argentina.

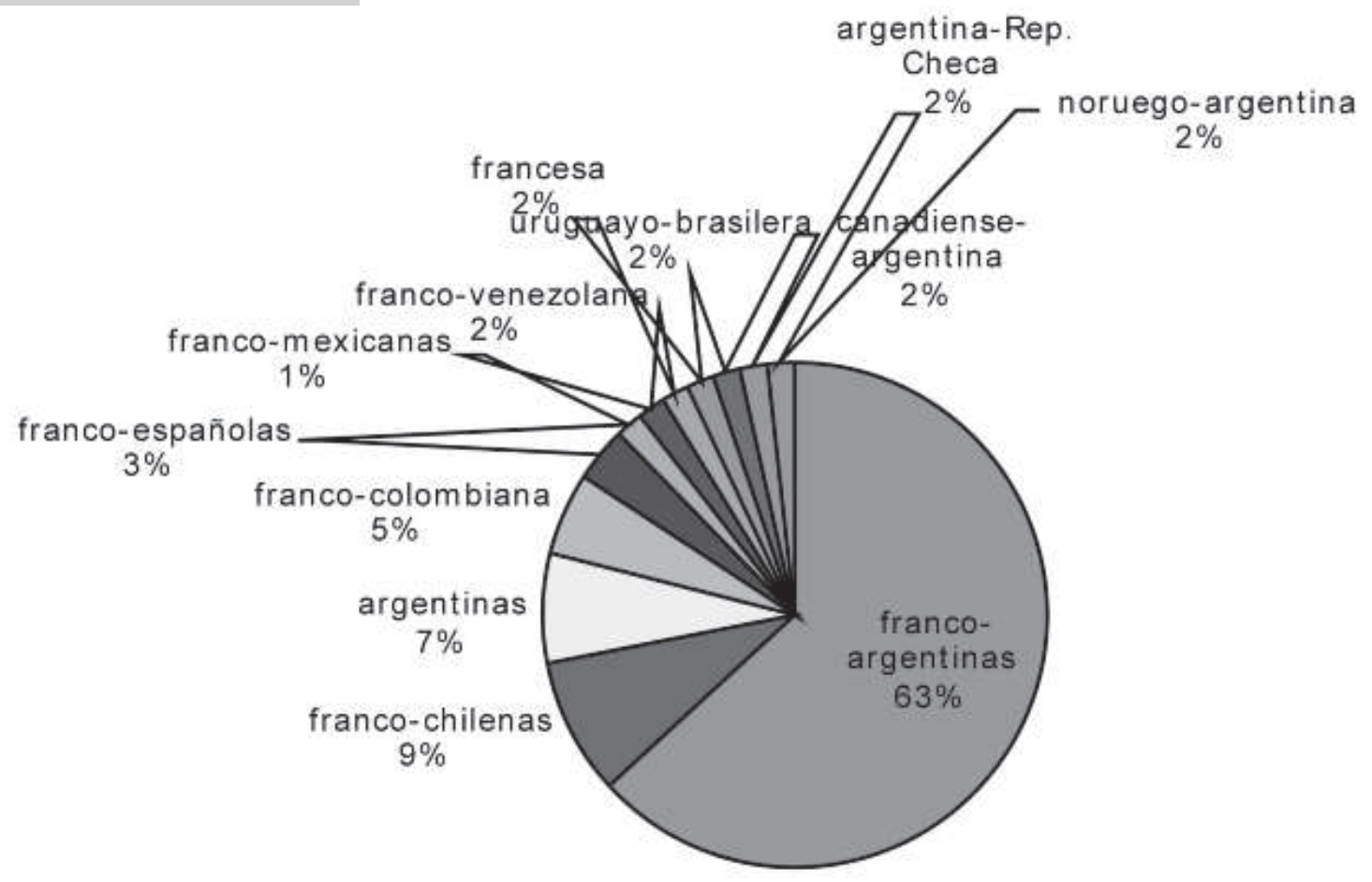


La experiencia de la Escuela Argentina en París.

L. BACK (EN COLABORACIÓN CON

L. Dumazet et M. Guerrien)

INSTITUCIONALIZACIÓN DEL PROYECTO ASOCIATIVO
La EAP es una institución anclada en dos países: frente a las autoridades argentinas es una escuela complementaria reconocida por el Ministerio de Educación (Resolución n 34 del 22/01/2010)ii. Dicho ministerio prevee la creación de escuelas complementarias en el mundo a través de asociaciones de padres que se organizan para su funcionamiento (1)iii. El ministerio argentino presenta solo exigencias formales; el financiamiento, la organización y el recorte de contenidos es terreno exclusivo de la asociación de padres.

Frente a las autoridades francesas, la EAP es una asociación sin fines de lucro, ley 1901. Esta misma se organiza como muchas asociaciones, con un Comité de Administración (CA) y un "bureau".

Desde el nacimiento, para los miembros fundadores, se imponía la instauración de un Otro-intitucional como lugar imprescindible de transmisión de la lengua-cultura.

El proyecto institucional se organizó así para favorecer su perenni$d a d$, y fue tomando forma gracias a decisiones ideológicas de fondo. La escuela debía abrirse a otras comunidades porque rechazamos la idea de constituirnos en gueto; no ser una escuela privada, privilegio de un grupo/clase socioeconómica, lo que nos obliga a ser creativos en su financiamiento; funcionar bajo un modelo asociativo sensible a la colaboración de familias de distintos horizontes; elegimos remunerar y profesionalizar un equipo pedagógico y reservar para la administración y la coordinación general los recursos voluntarios.

De igual manera, elegimos alojarnos en el seno de la educación francesa, un acuerdo entre la escuela, la Mairie de París y nuestra asociación nos ofrece la utilización de los espacios en la escuela pública, laica y republicana donde el idioma francés reina. Este acuerdo nos permite significar los puentes entre la cultura francesa y la cultura argentina y reconocernos como escuela francoargentina (acercamiento al equipo de docentes de la escuela francesa a través de su dirección, colaboraciones eventuales con el centre de loisirs, lazos con el barrio y la asociación de padres...)

El modelo de escuela complementaria no es original, estas escuelas complementarias son numerosas en París, escuelas búlgaras, rusas, japonesas, entre otras; tienen como objetivo acercar a los niños provenientes de familias mixtas a la lengua y a la cultura del país en cuestión.

Nuestra originalidad se encuentra, quizás, en la manera en que visualizamos el proyecto como una Alteridad/Entorno y en cómo elaboramos respuestas a partir de nuestras inquietudes en 
La experiencia de la Escuela Argentina en París.

L. BACK (EN COLABORACIÓN CON L. DUMAZET et M. GUerRiEN) diálogo permanente hacia el interior de la escuela (los chicos, los docentes, los padres) y hacia el exterior con otras instituciones, con artistas o profesionales de la educación, del bilingüismo y el psicoanálisis.

Por ejemplo, entendemos la complementariedad con la escuela francesa desde varios puntos de vista: no obligatoriedad, metodología, contenidos.

El proyecto gana la libertad que le brinda la complementariedad respecto a la escuela francesa obligatoria. El hecho de constituiírse como un complemento elegido por padres y niñosiv (2) permite a nuestra escuela diseñar un proyecto pedagógico a medida, contemplando la realidad en la que los chicos se desarrollan (doble filiación cultural y lingüística, tiempo, expectativas y exigencia de la escuela francesa, distancia geográfica con el país de origen...).

A nivel de la metodología, preferimos las pedagogías activas donde se borra la jerarquía entre el poder/saber del adulto vs. la ignorancia/pasividad del alumnov (3), para priorizar la posición deseante de los niños al concurrir a la EAP, su implicación afectiva frente a la lengua y a los contenidos. Ofrecer a los niños otro modelo de aprendizaje posible :: partir de la propia curiosidad para buscar y compartir el saber, con el otro diferente y parecido. Esta posición activa en la elaboración del proyecto se extiende a la selección de los contenidos, según un modelo democrático de funcionamiento, la asociación no delega el proyecto pedagógico en el equipo de docentes el proyecto pedagógico, tampoco lo "dirige". El proyecto institucional (asociativo) y los contenidos pedagógicos (equipo de profesionales de la educación) se entrelazan y se enriquecen por el trabajo de cada uno. Los nexos son múltiples.

Finalmente una colaboración estrecha con las familias es necesaria; si bien es el equipo pedagógico quien lleva adelante los programas de estudio; lael ida y vuelta con los padres es capital para la coherencia de la propuesta de la escuela. Estae se implementa a través de encuentros formales e informales, el cuaderno de los niños en los que los padres son invitados a compartir experiencias relevantes o acercar material cultural, la participación de padres o abuelos en las aulas.

El proyecto también resalta la valorización de todas las lenguas (y de las múltiples variaciones del español en Latinoamérica) sin jerarquías, estatutos o poderes (cantidades de hablantes o incsidencia en el mercado de consumo).

Por otra parte, sería un contrasentido pretender "enseñar" a los niños a ser francoargentinos, o francolatinoamericanos, ellos ya 
La experiencia de la Escuela Argentina en París.

L. BACK (EN COLABORACIÓN CON

L. Dumazet et M. GuerRien)

UN PROYEGTO PEDAGÓGICO A MEDIDA lo son, la posición de los docentes es la de acompañarlos a tomar consciencia de esta doble filiación, proporcionando el intercambio entre las experiencias y saberes propios, y dándoles a conocer otros aspectos de esta cultura lejana geográficamente, enriqueciéndose así adultos y niños.

Se desprende así un proyecto pedagógico centrado en la transmisión de la cultura argentina y latinoamericana en español. Elegimos no dar clases de español, sino dar clases en español, porque no se trabaja tomando la lengua como objeto de estudio. Lo pensamos como un gran baño de inmersión, un acercamiento en el corazón de París de un pedacito de Latinoamérica, donde los niños frecuentan otros parecidos (todos tienen una L1 y una L2) y diferentes a ellos mismos (la L2 no refiere en todos al mismo entorno lingǘstico y cultural: cambian los acentos, las razones por las que concurren a la escuela, las historias de vida, las identificaciones...).

La escuela se organiza en cinco grupos, de diecisietediez y siete a veinte niños cada uno, con dos docentes referentes por grupo facilitando el acompañamiento individualizado. Los grupos son constituidos por edades para adaptar los soportes y contenidos a la evolución de los niños, todos son mixtos :: 3 y 4 años, 5 y 6 años, 6 y 7 años, 8 a 10 años y 11 a 14 años.

Los contenidos elegidos se elaboran cada año., Eel equipo centra los proyectos de cada grupo en dos o tres ejes transversales para toda la escuela. Los contenidos se descartan de los programas de educación sugeridos por el Ministerio de educación argentino para cada ciclo escolar en los Núcleos de Aprendizajes Prioritarios. El recorte elegido por los docentes tiene en cuenta las particularidades de la población de la escuela y los lineamientos del proyecto institucional.

Sin manuales ni materiales específicos para la educación complementaria, los profesionales de la EAP diseñan sus propios programas, eligiendo los materiales (preferentemente actuales, escritos o hablados en español de latinoamérica), construyendo los soportes (en general lúdicos, no solo libros y cuadernos; sino también, viideo, fotografía, pintura, música, cocina) y la didáctica (en general basada en el paso por la experiencia personal :: el saber se desprende de una actividad que implica el cuerpo, la reflexión y el intercambio con el otro). En ese sentido, las clases favorecen actividades sensoriales, motrices y científicas.

Los docentes de distintas disciplinas (profesores de literatura, de plástica, de música, maestros jardineros, o docentes de primaria) 
La experiencia de la Escuela Argentina en París.

L. BACK (EN COLABORACIÓN CON

L. Dumazet et M. GuerRien)

CONCLUSIÓN trabajan en binomio, con un grupo de niños a cargo durante todo un año. Juntos crean un plan anual donde combinan recursos propios a su formación (por ejemplo un profesor de teatro y uno de literatura). Semana a semana van proponiendo disparadores alrededor de los cuales se desarrollará el año escolar :: leer una leyenda y teatralizarla (contextualizar su origen, conocer la cultura a la que está ligada, descubrir giros lingüísticos, crear los trajes para su representación, etc.), imaginar un viaje a la Patagonia proponiendo el armado de los folletos turísticos, imaginar el paso por la aduana y el viaje en avión (diferentes niveles de lengua, diferentes formatos de texto, un vocabulario específico), adaptar un cuento de García Marquez para filmar un cortometraje, o crear un guión colectivamente para una puesta teatral.

Los docentes, quienes son en su mayoría estudiantes argentinos de tercer ciclo instalados temporalriamente en París, son sensibilizados a la realidad particular de una población de familias mixtas, donde varias son las culturas y las lenguas que coexisten en el cotidiano afectivo de niños y adultos. Este acercamiento a la problemática de las familias de la EAP se realiza a través de formaciones con lingüistas, pedagogos, profesionales de la educación ;; pero sobre todo, de reuniones de equipo regulares donde los docentes, la coordinadora pedagógica, la secretaria de dirección, la directora y otro miembro representante del CA se encuentran una vez por mes. Esta reunión de trabajo permite reflexionar partiendo de las aulas, buscando recursos mutuos, creando nuevas salidas. Las mismas pueden también, de ser necesario, abordarse en las reuniones del CA. Así, de manera regular y conjunta se reelabora el proyecto entre el polo asociativo y el polo profesional.

La Escuela Argentina en París es en la actualidad un proyecto que busca responder a las inquietudes iniciales. ¿ Cómo transmitir una lengua-cultura 2 instalados en un contexto sociocultural francés?

En la elaboración de respuestas, seguimos nuestras intuiciones iniciales: "solos no podemos". Los niños nacen en una familia, los padres pertenecen a otras, las familias se arraigan a una sociedad. Por esto creemos que la transmisón de la lengua y la cultura no puede depender, ni debe reducirse a una tarea personal, debe más bien reflejar la construcción colectiva.

Para responder a la pregunta de la transmisión creamos una institución, un entorno-institucional argentino/latinoamericano en 
La experiencia de la Escuela Argentina en París.

L. BACK (EN COLABORACIÓN CON

L. Dumazet et M. Guerrien)
París. Un Otro capaz de significar a nuestros hijos que no es por mamá o por papá que hablan español ;; sino porque nacieron en el cruce de dos culturas, por ellos mismos.

Construir una escuela, es el legado a la comunidad de niños, con orígenes argentinos y latinoamericanos, de un Otro-institución capaz de acogerlos, donde puedan ellos mismos apropiarse, construir y deconstruir su identidad mixta en medio de una colectividad. La cultura y la lengua continúan su evolución y es conociéndolas y compartiéndolas con otros que se reavivan y se enriquecen.

\section{NOTAS}

(1) Resolución n 34 del 22/01/2010. Decreto n 371/79 del Plan de Educación Nacional.

(2) Efectivamente, los niños son invitados desde la entrevista de información previa a la inscripción a participar activamente, el cierre de cada año cuenta con un balance personal de cada niño y cada año renovamos los acuerdos con ellos y con sus familias el deseo de seguir siendo parte de la escuela.

(3) El modelo de educación en la escuela pública francesa permanece tradicional, con dos actores opuestos el "maître" que sabe y el alumno que no sabe. Despojando así los procesos de aprendizajes de la dimensión subjetiva. Como bien lo explica Meirieu: “ (...) le cours magistral plus ou moins dialogué demeure la forme dominante de communication, le travail en groupe est toujours aussi rare, le recours aux sanctions traditionnelles et punitions collectives est toujours privilégié, .... Ecouter, recopier, apprendre, réciter restent les activités principales. (...)" La machine-école, Philippe MEIRIEU, Gallimard, Paris, 2001.

i El Consejo de Administración de la EAP está compuesto por Paula, Betina, Luciana, Laura, Adriana, Romina, Lucía, Melisa y Liana.

\section{ii Resolución nº 34 del 22/01/2010.}

iii Resolución 184/2006, Decreto n 371/79 del Plan de Educación Nacional.

iv. Efectivamente, los niños son invitados desde la entrevista de información previa a la inscripción a participar activamente, el cierre de cada año cuenta con un balance personal de cada niño y cada año renovamos los acuerdos con ellos y con sus familias el deseo de seguir siendo parte de la escuela.

v. El modelo de educación en la escuela pública francesa permanece tradicional, con dos actores opuestos el "maître" que sabe y el alumno que no sabe. Despojando así los procesos de aprendizajes de la dimensión subjetiva. Como bien lo explica Meirieu: “ (...) le cours magistral plus ou moins dialogué demeure la forme dominante de communication, le travail en groupe est toujours aussi rare, le recours aux sanctions traditionnelles et punitions collectives est toujours privilégié, .... Ecouter, recopier, apprendre, réciter restent les activités principales. (...)" La machine-école, Philippe MEIRIEU, Gallimard, Paris, 2001. 